\title{
Quality of life in the first 100 days after suspected acute myocardial infarcation-a suitable trial endpoint?
}

John Rawles, Jane Light, Monika Watt

\begin{abstract}
Study objective-The aim was to determine the loss of quality of life following admission to hospital with suspected myocardial infarction.

Design-The study involved a cohort of admissions, with interview and follow up for 100 days. Main outcome measures were the quality of life prior to admission and at each stage of convalescence, estimated using the Rosser-Kind matrix: the calculated number of quality adjusted days during a $100 \mathrm{~d}$ follow up period.
\end{abstract}

Setting-The study took place in a teaching hospital in Scotland.

Patients-206 patients were admitted with suspected acute myocardial infarction. Infarction was confirmed in 160 ( $Q$ wave infarcts 100 , non- $Q$-wave infarcts 60 ), and unconfirmed in 46.

Main results-The quality of life scores before the suspected heart attack were similar for patients whose final diagnosis was $Q$ wave infarction, non-Q-wave infarction, or non-infarction. Of the 160 patients with confirmed infarction, only $54(34 \%)$ had regained their previous quality of life scores at the end of 100 days, compared with 26 of 46 $(57 \%)$ patients with unconfirmed infarction $(p<0.01)$. The mean numbers of quality adjusted days lost to patients with $Q$ wave infarction, non-Q-wave infarction, and non-infarction were $17 \cdot 0,12.4$, and 5.9 respectively (infarction $v$ non-infarction, $p<0.0001)$. Measurements of both quantity and quality of life contributed to these results.

Conclusions-The number of quality adjusted days lost after acute myocardial infarction is a practicable measurement that is relevant to patients' lives. It might be suitable as an outcome measure for clinical trials of thrombolytic therapy.

f Epidemiol Community Health 1992; 46: 612-616

Department of

Medicine and

Therapeutics,

University of

Aberdeen,

Foresterhill,

Aberdeen AB9 2ZD

United Kingdom

$\mathrm{J}$ Rawles

J Light

M Watt

Correspondence to:

Dr Rawles

Accepted for publication April 1992
Recent trials of thrombolytic therapy have highmeasures after acute myocardial infarction: the use of death necessitates very large numbers of patients ${ }^{1-3}$; the surrogate endpoints, left ventricular function ${ }^{4}$ and coronary artery patency, ${ }^{56}$ are only indirectly related to patient benefit, and angiography is not without risk ${ }^{7}$; and the use of left ventricular function may introduce a bias. ${ }^{8} \mathrm{~A}$ composite endpoint of death, or congestive heart failure, or extensive left ventricular damage has been used. ${ }^{9}$ lighted problems associated with outcome
Thrombolytic therapy reduces mortality, so that a small minority of patients live who would otherwise have died. By reducing infarct size, thrombolytic therapy might also be expected to improve the quality of life for the majority of patients who live, and who would have lived even without therapy. The outcome measure that is most relevant to the welfare of all patients would therefore be one that combines both quantity and quality of life.

Rosser and Kind have developed a numerical scale for assessing the quality of lif $\mathrm{e}^{10}$ which is highly reproducible ${ }^{1112}$ and has been used for the calculation of quality adjusted life-years, or QALYs. ${ }^{13}$ There has been much criticism of the use of QALYs by health economists as a means of determining the distribution of health care resources so as to maximise the return on expenditure. ${ }^{1415}$ The criticisms have been mostly of an ethical nature, concerning the trade off between quantity and quality of life, and the justice of distributing resources according to value for money. The quality of life scoring system itself, however, has not been seriously challenged. ${ }^{16}$

The scoring system is based on structured $4 \mathrm{~h}$ interviews with 70 subjects (20 patients, 20 nurses, 20 healthy volunteers, and 10 doctors) who were given descriptions of various combinations of disability and distress, and asked to rank them in order of severity of illness. They were also asked to say how much iller one patient was than another, as a ratio; the scoring matrix represents a consensus from these subjects, which has been normalised to give a range from 0 to $1 .{ }^{17}$

The most serious criticism of the Rosser-Kind matrix is that the scores have been derived from so few subjects, and even fewer patients. This criticism is particularly cogent since the subjects' experience of illness was especially important in determining their responses. The scores obtained have not been replicated. However, when applied to patients in a hospital study the measures were robust and sensitive to different medical teams and to changes in patients' states over time. When scores obtained from different sources were used, the conclusions about services did not differ. ${ }^{18}$

In this paper we use the Rosser-Kind scale to quantify the quality of life at each stage of convalescence after admission to hospital with suspected acute myocardial infarction. The number of days spent at any stage of convalescence is multiplied by the quality of life score at that stage to give the number of quality adjusted days. The total number of quality adjusted days in a 100 day follow up period is calculated and compared with the expected number based on an assessment of the quality of life prior to admission to hospital. 


\section{Methods}

Two hundred and six consecutive patients were studied, 142 men and 64 women, mean age 63 years (range 32-93). All patients were considered by their general practitioners to have a strong probability of acute myocardial infarction, having had typical chest pain for between 20 minutes and four hours. In hospital the diagnosis was sought by electrocardiography and measurement of the myocardial isoenzyme of creatine kinase (CKMB). Of 206 patients, acute myocardial infarction was diagnosed in 160,100 by the appearance of $Q$ waves on the electrocardiogram, and 60 by the development of electrocardiographic changes other than $\mathrm{Q}$ waves, or elevation of CK-MB above the upper limit of normal. In 46 patients acute myocardial infarction was not confirmed: ischaemic heart disease was present in 20 , and no cause was found for the chest pain in 22; two patients had pericarditis, one had biliary colic, and one (who died) had a dissection of the proximal aorta. Thus there were 160 patients with acute myocardial infarction, 100 with $Q$ waves, 60 without, and 46 with non-infarction.

The progress of patients in hospital was noted, the dates being recorded when patients were allowed out of bed, and when they were discharged home. Before discharge, patients were interviewed by a doctor (JR) who had no clinical responsibility for them and did not give advice on rehabilitation. The purpose of the interview was to assess the quality of life prior to admission, to request cooperation during follow up, and to give each patient a letter on which to record the dates when various activities were resumed after discharge from hospital. One month after admission patients were contacted (by JR), usually by telephone, and their progress noted. Any readmissions during the notional 100 day follow up period, for example because of reinfarction or cardiac failure, were logged in the same way as the initial admission. A final interview and examination was made three months after the suspected heart attack.

THE QUALITY OF LIFE SCALE

Table I shows the Rosser-Kind scale as adapted for use in this study. The original valuation matrix consists of eight levels of disability combined with four degrees of mental distress (none, mild, moderate, or severe, A to D). Level one is no disability, while level two is slight social handicap, such as not being allowed to drive during convalescence from myocardial infarction in spite of full physical recovery. The third and fourth levels of disability mark slight or severe limitation of work capacity, either paid employment or housework, whichever is appropriate considering age and social position. The fifth level of disability is such that might be experienced when first discharged home after acute myocardial infarction-being confined to home except for escorted outings, and undertaking only the lightest of household tasks. Level six disability is being in hospital, allowed up, but spending most of the day in a chair or in bed, and moving around only under supervision. Level seven is being confined to bed, as on admission to hospital with suspected acute myocardial infarction. We have omitted the the highest degree of disability, which is unconsciousness.

In order to avoid the necessity for repeated questioning of patients with recent infarction about their degree of mental distress, the assumption is made that moderate distress will be experienced while the patient is confined to bed on first admission to hospital, and mild distress will be experienced once the patient is allowed out of bed. Mild distress at least is assumed until disability improves to level four or better.

Each combination of level of disability and degree of distress is associated with a quality of life score which ranges from 0 to 1 .

As laid out, the table may be used to record the dates of each stage of convalescence as the patient progresses from admission to hospital with suspected acute myocardial infarction (quality of life $7 \mathrm{C}=0.000$ ), to restoration to full health with no disability or distress (quality of life $1 \mathrm{~A}=1 \cdot 000$ ). The same table is used to determine the quality of life score prior to the suspected heart attack.

The figure shows a plot of the quality of life scores of two patients during the 100 days following admission to hospital. The upper horizontal line indicates the score prior to admission, and the stepped line indicates the improvement in quality of life from admission on day 0 , until the end of the follow up period. The area under the stepped line indicates the number of quality adjusted days attained during 100 days, and the shaded area gives the number of quality adjusted days lost. In these examples the scores prior to the
Table I Modified Rosser-Kind scale for assessing the quality of life (QOL) after admission to hospital with suspected acute myocardial infarction

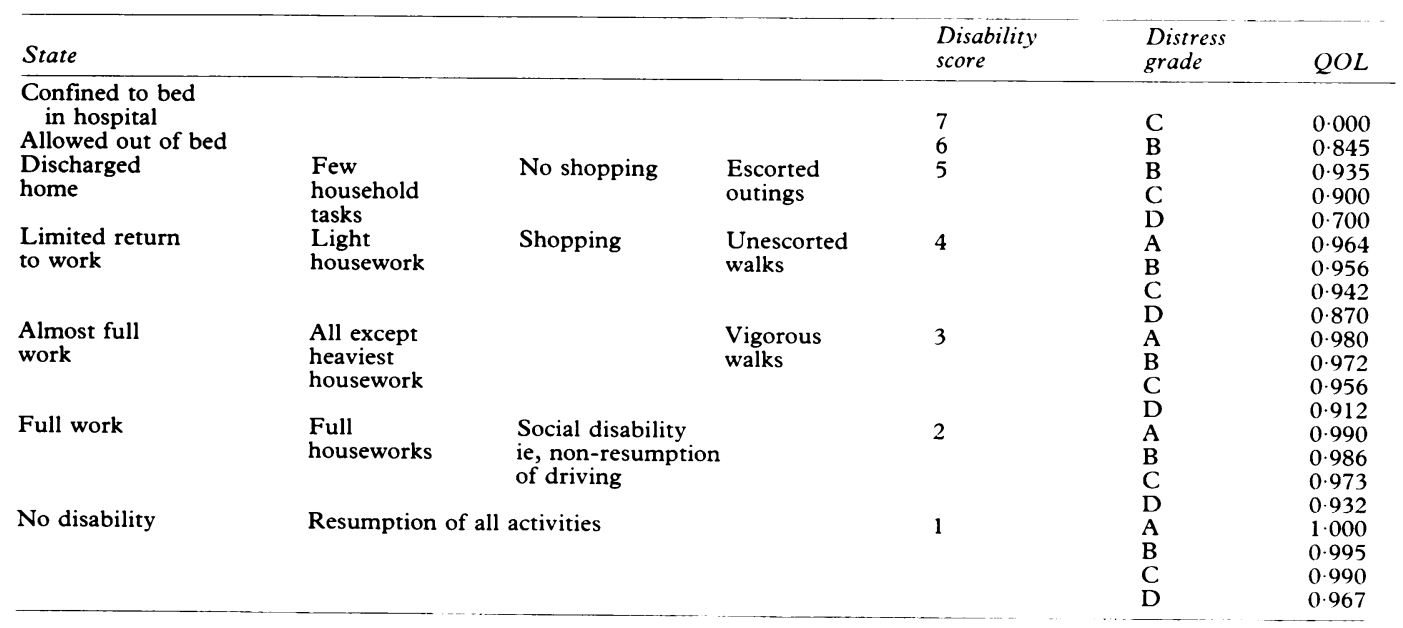


Quality of life (ordinate $0-1)$ at each stage of convalescence after admission to hospital with suspected acute myocardial infarction, which was confirmed (right), and not confirmed (left). The shaded area gives the number of quality adjusted days ( $Q A D$ ) lost during the 100 day follow up period.
Table II Numbers of patients who regained their preadmission quality of life by 100 days after suspected acute myocardial infarction

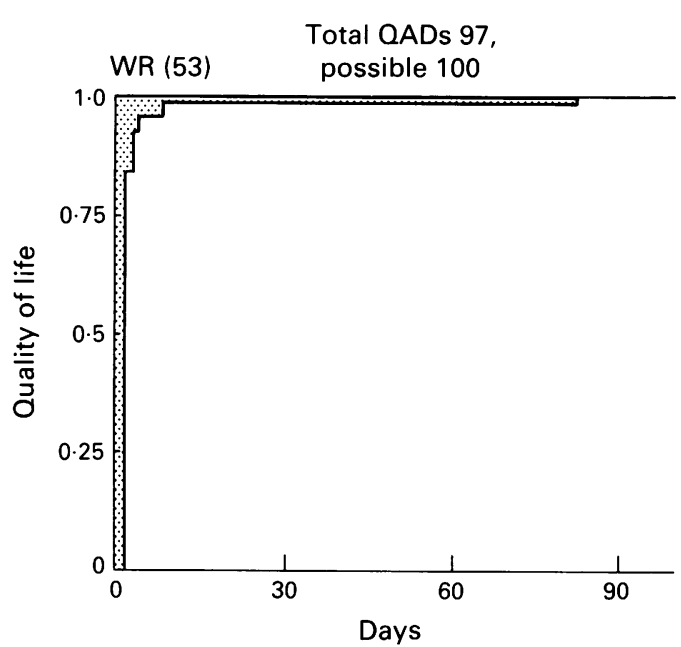

suspected heart attack were the same $(1 \cdot 0)$, but the patient in whom myocardial infarction was confirmed (right) did not regain his previous quality of life score by 100 days, and sustained a greater loss of quality adjusted days than the patient in whom the diagnosis was not confirmed (left).

\section{STATISTICAL METHODS}

Wilcoxon's test was used for comparison of paired and unpaired data. Statistical significance is taken as $\mathrm{p}<0.05$.

\section{Results}

Twenty one patients died, 15 with $Q$ wave infarction, five with non-Q-wave infarction, and one with non-infarction. The number of patients who regained their preadmission quality of life scores by 100 days was significantly fewer in those with confirmed infarction than in those without. This is true for all patients (including those who died) $\left(\chi^{2}=7 \cdot 80, p<0.01\right)$, and for those patients who were alive at 100 days $\left(\chi^{2}=5 \cdot 12, p<0.05\right)$, table II.

In table III the mean quality of life scores before admission and at 100 days are given. The scores before admission were not significantly different between groups with different final diagnoses. For all patients with myocardial infarction (including those who died), and for the subgroup who were alive at 100 days, the mean quality of life scores were significantly lower at 100 days compared with their preadmission values. By contrast, the preadmission and 100 day scores for patient with non-infarction were not significantly different.

The 100 day quality of life scores tended to be lower for patients with infarction than for those without infarction, in all patients $(p<0.01)$, and in those who lived $(p=0.07)$.

Table IV gives the mean number of quality adjusted days lost per patient during the 100 day follow up period. For all patients with myocardial

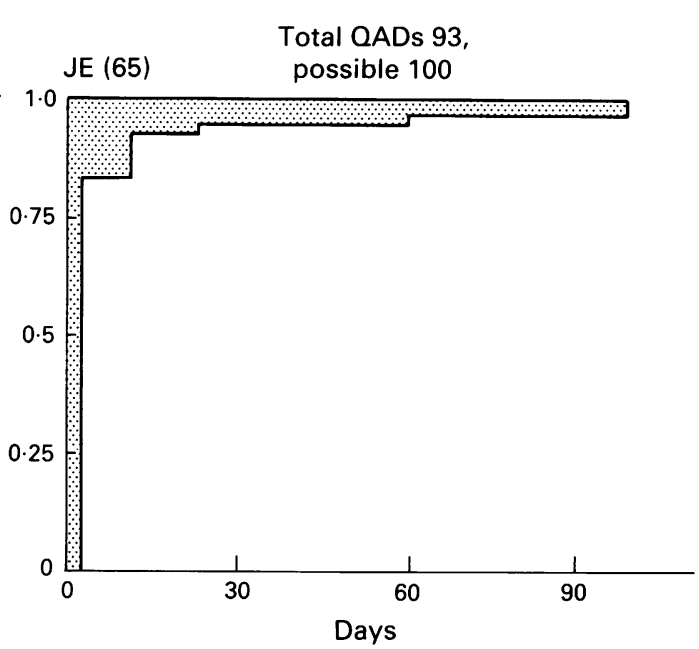

infarction, 15.3 quality adjusted days were lost, compared with 5.9 for those with non-infarction $(p<0.0001)$. This difference is largely due to the higher mortality rate in those with infarction, but $16 \%$ of the difference is contributed by the greater loss of quality adjusted days in infarct than in non-infarct patients who were alive at 100 days $(5.3 v 3.8, \mathrm{p}<0.001)$. Since the 100 day quality of life score was not significantly different in infarct and non-infarct patients who lived $(p=0.07)$, this highly significant difference in the loss of quality adjusted days was due to a longer time spent at a lower quality of life at an earlier stage of convalescence by patients with confirmed infarction.

Within the group of patients with myocardial infarction, comparisons of those with $Q$ wave and non-Q-wave infarction revealed no significant differences, though there was a tendency for mortality to be higher with $Q$ wave infarction.

\section{Discussion}

Thrombolytic therapy, given during the evolution of myocardial infarction, is believed to make infarcts smaller than they would have been without intervention. The benefits of therapy therefore depend on the projected infarct size without treatment. If this is large there is reduction of mortality, if intermediate there is improved left ventricular function, and if small the infarct may be aborted or made undetectable. While reduction of mortality from large infarcts increases the quantity of life, the preservation of left ventricular function and the aborting of infarction might be expected to increase the quality of life. If it were not for the adverse effects of thrombolytic therapy, particularly the liability to cause haemorrhagic stroke, its use could be advocated for evolving infarcts whatever their size. However, because reduction of mortality with thrombolytic therapy has not been demonstrated in small infarcts, identified by minor electrocardiographic abnormalities short of ST segment elevation, the

\begin{tabular}{|c|c|c|c|c|c|c|c|c|c|c|}
\hline & & \multicolumn{3}{|l|}{ Lived } & \multicolumn{3}{|l|}{ Died } & \multicolumn{3}{|l|}{ All } \\
\hline & & Yes $\left(o_{0}\right)$ & No & Total & Yes & No & Total & Yes $\left(\sigma_{0}\right)$ & No & Total \\
\hline Myocardial infarction & $\begin{array}{l}\text { Q wave } \\
\text { Non-Q-wave } \\
\text { All MI }\end{array}$ & $\begin{array}{l}34(40) \\
20(36) \\
54(39)\end{array}$ & $\begin{array}{l}51 \\
35 \\
86\end{array}$ & $\begin{array}{r}85 \\
55 \\
140\end{array}$ & $\begin{array}{l}0 \\
0 \\
0\end{array}$ & $\begin{array}{r}15 \\
5 \\
20\end{array}$ & $\begin{array}{r}15 \\
5 \\
20\end{array}$ & $\begin{array}{l}34(34) \\
20(33) \\
54(34)\end{array}$ & $\begin{array}{r}66 \\
40 \\
106\end{array}$ & $\begin{array}{r}100 \\
60 \\
160\end{array}$ \\
\hline Non-myocardial infarction & & $26(58)$ & 19 & 45 & 0 & 1 & 1 & $26(57)$ & 20 & 46 \\
\hline Total & & $80(43)$ & 105 & 185 & 0 & 21 & 21 & $80(39)$ & 126 & 206 \\
\hline
\end{tabular}


Table III Preadmission and 100 day quality of

life scores for patient

with suspected acute

myocardial infarction.

Values are means (SD)

\begin{tabular}{|c|c|c|c|c|c|}
\hline & & Number & Preadmission & 100 day & $p$ \\
\hline Myocardial infarction & $\begin{array}{l}\text { Q wave } \\
\text { Non-Q-wave } \\
\text { All MI }\end{array}$ & $\begin{array}{r}100 \\
60 \\
160\end{array}$ & $\begin{array}{l}0.980(0.021) \\
0.973(0.044) \\
0.977(0.032)\end{array}$ & $\begin{array}{l}0.820(0.348) \\
0.885(0.272) \\
0.844(0.322)\end{array}$ & $\begin{array}{l}<0.0001 \\
<0.0001 \\
<0.0001\end{array}$ \\
\hline Non-myocardial infarction & & 46 & $0.978(0.022)$ & $0.953(0.145)$ & NS \\
\hline Total & & 206 & $0.977(0.030)$ & $0.869(0.295)$ & $<0.0001$ \\
\hline
\end{tabular}

opinion is hardening that the risk-benefit ratio of thrombolytic therapy is unacceptable in such cases. But a range in end points is needed to assess all the possible benefits of treating infarcts of different sizes, and it may be inappropriate to rely on mortality alone to determine the risk-benefit ratio of treating small infarcts.

The spectrum of possible benefits of thrombolytic therapy is very wide, including a reduction of mortality, less cardiac failure, improved exercise capacity, and earlier return to normal activities. If acute myocardial infarction is suspected but not confirmed there may be benefits of a different sort for the patient, who spends less time in hospital and may return to work sooner; the distress of being labelled as having ischaemic heart disease is obviated, and restrictions on driving or sexual intercourse are not imposed.

Apart from measurement of mortality, the outcome of thrombolytic therapy has been assessed by measurement of coronary artery patency or left ventricular function. But these physiological measures may have little bearing on how the patient feels or behaves. Disease specific measures of patient activity might be used, such as the New York Heart Association functional classification, ${ }^{19}$ the specific activity scale, ${ }^{20}$ or indices for the measurement of dyspnoea. ${ }^{21}$ However, these measures of physical function are difficult to combine in a unitary scale with death, the worst outcome of myocardial infarction, and are completely insensitive to the psychological and social consequences of the illness.

Health profiles are instruments for assessing the most important aspects of living that determine the quality of life, and include the sickness impact profile, ${ }^{22}$ the Nottingham health profile, ${ }^{23}$ and the McMaster health index questionnaire. ${ }^{24}$ But because they utilise a large number of questions, health profiles are unsuitable for repeated application during recovery from acute myocardial infarction. Moreover, the responses are not always summed into a single score.

In this study we have applied the Rosser-Kind scale to the measurement of the quantity and quality of life after admission to hospital with suspected acute myocardial infarction. Patients with infarcts of all sizes are represented in the series: large $Q$ wave infarcts, of which $15^{\circ}{ }_{0}$ were fatal; smaller, non-Q-wave infarcts, with a mortality rate of $8 \%$; and non-infarcts, in whom infarction was suspected but not confirmed (mortality $2 \%$ ).
The modified Rosser-Kind scale uses seven levels of disability, determined objectively, and four subjective degrees of mental distress. Because the level of disability contributes much more to the quality of life score than the degree of mental distress, the retrospective assessment of the quality of life before admission should not be seriously biased. The quality of life during recovery from myocardial infarction is assessed prospectively, but while the patient is in hospital it is determined solely by the level of disability, assumed levels of distress being used.

A deficiency of the Rosser-Kind scale is that no distinction is made between death and a poor quality of life characterised by being confined to bed and suffering moderate distress, both states scoring zero. This raises serious problems if the scale is used for comparing the outcomes from different therapies that are palliative or life saving, for example, hip replacement or heart transplantation. The implicit value of life is merely the absence of suffering, and the low valuation placed on life leads to absurdities when quantity and quality of life are traded for each other. ${ }^{25}$ But in suspected acute myocardial infarction, both quantity and quality of life are altered in the same direction by therapy, so that quantity and quality can be compounded. The resultant loss of quality adjusted days is heavily weighted by those who die compared with the loss of quality of life in survivors. Thus, on average, patients who died lost 86 quality adjusted days, while those who lived lost five. This weighting goes some way to remedying the low valuation placed on life by the scale, and arises because quality of life scores cluster around 0.9 for most of the convalescent period, but the state of being dead, and its zero score, persists throughout follow up. The weighting for death would therefore be increased further if a longer follow up period were used, but the measure would then be less sensitive to differences in the quality of life of those who live.

The loss of quality adjusted days might therefore be usable as an outcome measure to assess the benefits of treatment intended to reduce the size of infarcts of all magnitudes and mortality risks. Adverse effects of treatment, if they impinge on the quality or quantity of life, are included in the total number of quality adjusted days lost. The gains and losses of therapy are therefore computed in the same currency as each other, enabling the risk-benefit ratio to be calculated for any subgroup of patients.

It might be considered that a death that occurs as a result of administering thrombolytic therapy
Table IV Loss of quality adjusted days (QAD) for patients with suspected acute myocardial infarction myocardial infarction.
Values are mean $(S D)$.

\begin{tabular}{|c|c|c|c|c|c|c|c|}
\hline \multirow[b]{3}{*}{ Myocardial infarction } & \multirow[b]{3}{*}{$\begin{array}{l}Q \text { wave } \\
\text { Non-Q-wave } \\
\text { All } M I\end{array}$} & \multicolumn{2}{|l|}{ Lived } & \multicolumn{2}{|l|}{ Died } & \multicolumn{2}{|l|}{ All } \\
\hline & & \multirow{2}{*}{$\begin{array}{c}\text { Number } \\
85 \\
55 \\
140\end{array}$} & \multirow{2}{*}{$\begin{array}{l}Q A D \\
5.09(2.34) \\
5.65(4.58) \\
5.31(3.40)\end{array}$} & \multicolumn{2}{|c|}{ Number $\left(0_{0}^{\circ}, Q A D\right.$} & Number & $Q A D$ \\
\hline & & & & $\begin{array}{l}15(15) \\
5(8) \\
20(13)\end{array}$ & $\begin{array}{l}84 \cdot 67(22 \cdot 7) \\
86 \cdot 60(13 \cdot 0) \\
85 \cdot 15(20 \cdot 4)\end{array}$ & $\begin{array}{r}100 \\
60 \\
160\end{array}$ & $\begin{array}{l}17.03(29.9) \\
12.40(23 \cdot 2) \\
15.29(27 \cdot 6)\end{array}$ \\
\hline Non-myocardial infarction & & 45 & $3.78(2.09)$ & $1(2)$ & $100 \cdot 0 \quad(0.00)$ & 46 & $5 \cdot 87(14 \cdot 3)$ \\
\hline Total & & 185 & $4 \cdot 94(3 \cdot 19)$ & $21(10)$ & $85 \cdot 86(20 \cdot 1)$ & 206 & $13 \cdot 19(25 \cdot 5)$ \\
\hline
\end{tabular}


is not equivalent to one that occurs because therapy is withheld. If that is felt to be the case, then any quality adjusted days lost due to an adverse reaction to therapy could be increased by a factor which would take this sentiment into account.

In this study, there was a gradient of lost quality adjusted days during the 100 day follow up period, their number being greatest for those with $Q$ wave infarction, intermediate for those with non-Q-wave infarction, and least for those with non-infarction. Those who died lost the greatest number of quality adjusted days, while those who lived lost more quality adjusted days if infarction was confirmed than if it was not. Since this is a new measure in this condition there is no gold standard with which to make comparisons, but the results obtained are what would be expected of a satisfactory gauge of the quality and quantity of life.

It is noteworthy that the numbers of quality adjusted days lost to patients with $Q$ wave and non- $Q$-wave infarction who survive are not significantly different. This could be because the measurement of lost quality adjusted days is not very sensitive to small differences in the quality of life, or that any physiological differences between patients with $Q$ wave and non- $Q$-wave infarcts are not translated into changed quality of life. The latter is most probably the case, since the rate at which a patient convalesces is determined less by limitations of physiology than by restrictions imposed by his physician, which are based on custom and culture. It might be objected, therefore, that the measurement of lost quality adjusted days is arbitrary and artificial, and unrelated to patients' physiological status. Nevertheless, the outcome measure we propose is more closely related to patient welfare than the so called surrogate measures that have been employed previously.

Our results suggest that the theoretical benefits of a non- $Q-W a v e$ rather than a $Q$ wave infarct may not result in improved quality of life. If the survivors of infarction are to reap the full benefits of a therapy which makes a large infarct smaller, more attention may need to be paid to rehabilitation. On the other hand, there are clear benefits in having a small infarct made undetectable, since, if infarction is not confirmed, fewer restrictions are placed on patients and the previous quality of life is regained sooner.

We thank Mrs Joy McKnight for her invaluable assistance; she is supported by a Research Grant from Grampian Health Board, which is gratefully acknowledged.
1 Gruppo Italiano per lo studio della streptochinasi nell' infarto miocardico (GISSI). Effectiveness of intravenou thrombolytic treatment in acute myocardial infarction Lancet 1986; i: 397-401.

2 Second international study of infarct survival collaborative group. Randomised trial of intravenous streptokinase: ora asprin, both, or neither among 17187 cases of suspected acute myocardial infarction: ISIS-2. Lancet 1988; ii: acute my-60.

3 Wilcox RG, von der Lippe G, Olsson CG, Jensen G, Skene $A M$, Hampton JR. Trial of tissue plasminogen activator for mortality reduction in acute myocardial infarction. Lancet 1988; ii: $525-30$.

4 Sheehan FH. Measurement of left ventricular function as an endpoint in trials of thrombolytic therapy. Coronary Artery Dis 1990; 1: 13-22.

5 Chesebro JH, Knatterud G, Roberts R, et al. Thrombolysis in myocardial infarction (TIMI) trial, phase I: a in myocardial infarction (TIMI) trial, phase $\mathrm{I}$ : comparison between intravenous tissue plasminogen
activator and intravenous streptokinase. Circulation 1987; 76: $142-54$.

6 Hogg KJ, Gemmill JD, Burns JMA, et al. Angiographic patency study of antistreplase versus streptokinase in acute myocardial infarction. Lancet 1990; 335: 254-8.

7 Anonymous. Surrogate measures in clinical trials. Lancet 1990; 335: 261-2.

8 Van de Werf F. Discrepancies between the effects of coronary reperfusion on survival and left ventricular function. Lancet 1989; i: 1368-9.

9 Gruppo Italiano per lo Studio della Sopravvivenza nell' Infarto Miocardico. GISSI-2: A factorial randomised trial of alteplase versus streptokinase and heparin versus no heparin among 12490 patients with acute myocardial infarction. Lancet 1990; 336: 65-71.

10 Rosser R, Kind P. A scale of valuations of states of illness: is there a social consensus? Int $\mathcal{F}$ Epidemiol 1978; 7: 347-58.

11 Rosser RM, Watts VC. The measurement of hospital output. Int $\mathcal{f}$ Epidemiol 1972; 1: 361-8.

12 Benson TJR. Classification of disability and distress by ward nurses: a reliability study. Int $\mathcal{f}$ Epidemiol $1978 ; 7: 359-61$.

13 Wurses: a reliability study. Int $\mathcal{f}$ Epidemiol $1978 ; 7: 359-61$. WMF 1985; 291: 326-9.

14 Harris J. QALY fying the value of life. $\mathcal{F}$ Med Ethics 1987; 13: $117-23$.

15 Smith A. Qualms about QALYs. Lancet 1987; i: 1134-6. Fallowfield $\mathrm{L}$. The quality of life. The missing measurement in health care. London: Souvenir Press (Education and Academic Ltd), 1990

17 Kind P, Rosser R, Williams A. Valuation of quality of life: some psychometric evidence. In: Jones-Lee MW, ed. The value of life and safety. Amsterdam: North Holland, 1982: 159-70.

18 Rosser R. A history of the development of health indicators. In: Smith GT, ed. Measuring the social benefits of medicine. London: Office of Health Economics, 1984: 50-61.

19 Harvey RM, Doyle EF, Ellis K, et al. Major changes made by Criteria Committee of the New York Association. Circulation 1974; 49: 390.

20 Goldman L, Hashimoto B, Cook EF, Loscalzo A. Comparative reproducibility and validity of systems for assessing cardiovascular functional class: advantages of a new specific activity scale. Circulation 1981; 64: 1227-34.

21 Mahler DA, Weinberg DH, Wells CK, Feinstein AR. The measurement of dyspnoea. Contents, interobserver agreement, and physiologic correlates of two new clinical indexes. Chest 1984; 85: 751-8.

22 Bergner M, Bobbitt RA, Carter WB, Gilson BS. The Sickness Impact Profile: Development and final revision of Sickness Impact Profile: Development and final revision

23 Hunt SM, McKenna SP, McEwen J, Backett EM, Williams J, Papp E. A quantitative approach to perceived health status: a validation study. $f$ Epidemiol Community Health 1980; 34: 281-6.

24 Sackett DL, Chambers LW, MacPherson AS, Goldsmith $\mathrm{CH}$, McAuley RG. The development and application of indices of health: general methods and a summary of results. Am $\mathcal{F}$ Public Health 1977; 67: 423-8.

25 Rawles JM. Castigating QALYs. f Med Ethics 1989; 15: 143-7. 